\title{
Hedyotis diffusa Willd. inhibits VEGF-C-mediated lymphangiogenesis in colorectal cancer via multiple signaling pathways
}

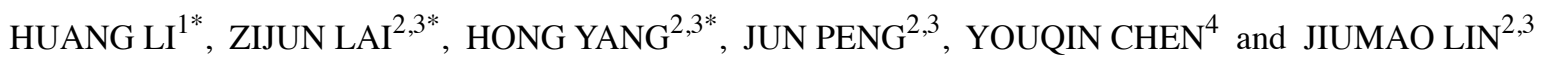 \\ ${ }^{1}$ College of Pharmacy, ${ }^{2}$ Academy of Integrative Medicine, and \\ ${ }^{3}$ Fujian Key Laboratory of Integrative Medicine on Geriatrics, Fujian University of Traditional Chinese Medicine, \\ Fuzhou, Fujian 350122, P.R. China; ${ }^{4}$ Case Western Reserve University School of Medicine, \\ Rainbow Babies and Children's Hospital, Cleveland, OH 44106, USA
}

Received January 12, 2019; Accepted July 3, 2019

DOI: 10.3892/or.2019.7223

\begin{abstract}
Colorectal cancer (CRC) is one of the most commonly diagnosed malignancies worldwide. For patients diagnosed with the presence of metastatic disease, surgery is not suitable for the majority of them. Lymphangiogenesis is a key factor during cancer metastasis and is regulated by vascular endothelial growth factor C (VEGF-C). Hedyotis diffusa Willd. (HDW) is a Chinese herb of the Rubiaceae family that reportedly inhibits tumor metastasis. However, its underlying anticancer mechanisms have not yet been elucidated. In the present study, we investigated the effects of an ethanol extract of HDW (EEHDW) on the migration capacity by wound healing and Transwell assays, and the effect on the VEGF-C expression in different CRC cell lines by western blot analysis and ELISA assays. A model of VEGF-C-stimulated human lymphatic endothelial cells (HLECs) was constructed. It was found that EEHDW suppressed lymphangiogenesis via the mediation of multiple pathways, which attenuated the migration of cells and their tube formation abilities. Multiple signaling pathways were found to be involved in the VEGF-C-mediated lymphangiogenesis. After EEHDW treatment in VEGF-C-stimulated HLECs, EEHDW was found to downregulate the expression levels of multiple signaling pathways. Taken together, these results indicate that EEHDW possesses significant anti-metastatic activities. Moreover, the suppressive effect of EEHDW on lymphangiogenesis, particularly via downregulation of VEGF-C, partly explains
\end{abstract}

Correspondence to: Dr Jiumao Lin, Academy of Integrative Medicine, Fujian University of Traditional Chinese Medicine, 1 Qiuyang Road, Minhou Shangjie, Fuzhou, Fujian 350122, P.R. China

E-mail: linjiumao@fjtcm.edu.cn

${ }^{*}$ Contributed equally

Key words: Hedyotis diffusa Willd., colorectal cancer, metastasis, lymphangiogenesis, VEGF-C the potential molecular mechanism underlying the inhibitory effect of EEHDW on CRC metastasis.

\section{Introduction}

Colorectal cancer (CRC) ranks as the third most commonly diagnosed cancer and fourth leading cause of cancer-related death worldwide $(1,2)$. Surgery and chemotherapy are the most common therapeutic strategies for CRC, but they are frequently associated with adverse side effects (3). However, the low efficacy of these treatments in advanced stage CRC patients is a serious public concern due to the high mortality rate. The limited efficacy of these therapies is mainly due to lymph node metastasis (4). At the time of diagnosis, approximately $25 \%$ of CRC patients present with metastatic disease, and the 5 -year survival rate is approximately $10 \%$ (5). Therefore, to reduce $\mathrm{CRC}$-associated mortality through the development of therapeutic agents, it is critical to elucidate the mechanisms underlying tumor metastasis.

Among many solid malignancies, the dissemination of cancer cells is mainly by means of lymphatic metastasis (6-10). Thus, a crucial target for anti-metastatic agents is tumor lymphangiogenesis. Lymphangiogenesis is a complex multi-stage process including proliferation, survival, migration and tube formation of endothelial cells, which depends largely on the signaling of vascular endothelial growth factor $\mathrm{C}$ (VEGF-C) and VEGF receptor 3 (VEGFR3) $(11,12)$. VEGF-C is a member of the platelet-derived growth factor family (11). VEGFR3 is a tyrosine kinase receptor that is expressed in human lymphatic endothelial cells (HLECs) (13). After the binding of VEGF-C to VEGFR3, downstream pathways, including PI3K/AKT, ERK and STAT3, are activated, leading to the growth of endothelial cells or to proliferation, survival, migration, and tube formation of endothelial cells and subsequent lymphangiogenesis and metastasis. Thus, expression of VEGF-C is a key for determining whether a tumor has metastasized (14).

Hedyotis diffusa Willd. (HDW) is a well-known member of the Rubiaceae family of tropical herbs, shrubs, and trees. HDW is known for its properties of heat-clearing and detoxification 
(in Chinese, Qing Re Jie Du), promotion of blood circulation and the removal of blood stasis (in Chinese, Huo Xue Hua Yu); therefore, it is widely used as a toxin-clearing herb in traditional Chinese medicine (15-17). According to a previous report, an ethanol extract of HDW (EEHDW) was found to inhibit the growth of colon cancer by inhibiting cell proliferation, tumor angiogenesis and metastasis; and it promoted cell apoptosis via regulation of multiple signaling pathways (18-21). However, the mechanisms underlying the anti-metastatic effect of HDW have not been elucidated, especially regarding lymphangiogenesis. In the present study, by using various CRC cell lines and applying a VEGF-C-stimulated HLEC model, the effects of EEHDW on tumor metastasis and lymphangiogenesis were investigated.

\section{Materials and methods}

Preparation of an ethanol extract of Hedyotis diffusa Willd. The preparation of EEHDW was carried out using the same procedure as previously described (22). Briefly, EEHDW powder was dissolved using $100 \%$ DMSO. The concentration of EEHDW was $500 \mathrm{mg} / \mathrm{ml}$ and was stored at $-20^{\circ} \mathrm{C}$. The same volume of DMSO was administered to all control groups in this study.

Cell culture. Human colorectal carcinoma cell lines HCT116 (Cell Bank of the Chinese Academy of Sciences, Shanghai, China), HCT-8 (Nanjing Keygen Biotech, Jiangsu, China) and HLECs (JNO-19268; Jennio Biotech Company, Guangdong, China) were cultured in RPMI-1640 (cat. no. C11875500BT, Thermo Fisher Scientific, Inc., Waltham, MA, USA) medium containing $10 \%$ (v/v) fetal bovine serum(FBS; cat.no. 10099-141, Thermo Fisher Scientific, Inc.), $1 \%$ penicillin-streptomycin (cat. no. SV30010, Thermo Fisher Scientific, Inc.), and then cultured in a $37^{\circ} \mathrm{C}$ humidified incubator with $5 \% \mathrm{CO}_{2}$.

Administration of EEHDW and exogenous VEGF-C. CRC cells were seeded into 6 -well plates $\left(2.5 \times 10^{5}\right.$ cells/well $)$ for $12 \mathrm{~h}$, and were subsequently treated with EEHDW for the indicated times as specified for the MTT, colony formation, flow cytometry, Transwell, tube formation and western blot assays. HLECs were grown until achieving $~ 60 \%$ confluency in complete medium and then the medium was replaced with FBS-free medium overnight. The cells were then placed into another complete medium which contained $2 \%$ FBS; and then the cells were treated with $5 \mathrm{ng} / \mathrm{ml}$ VEGF-C (cat. no. CYT-527, Prospec-Tany TechnoGene, Ltd., East Brunswick, NJ, USA) and/or various doses of EEHDW for the indicated times.

Cell viability assay. MTT assays were used to detect cell viability. Firstly, cells were plated into a 96-well ( $1 \times 10^{5}$ cells/well) overnight, and then the cells were treated with $\operatorname{EEHDW~}(0,0.125,0.25,0.5$ and $1,2 \mathrm{mg} / \mathrm{ml})$ and/or exogenous VEGF-C ( $5 \mathrm{ng} / \mathrm{ml})$ for $24 \mathrm{~h}$; then MTT $(0.5 \mathrm{mg} / \mathrm{ml})$ was added to each well (100 $\mu \mathrm{l} /$ well) and incubated for $4 \mathrm{~h}$. Subsequently, all wells were treated with DMSO (100 $\mu \mathrm{l} /$ well). An ELISA reader (Infinite M200 PRO; Tecan Austria GmbH, Austria) was used to read the absorbance $(570 \mathrm{~nm})$. This experiment was repeated eight times.
Colony formation assay. The procedures were conducted in the same way as previously described (15). Briefly, after pretreatment with $\operatorname{EEHDW}(0,0.125,0.25,0.5$ and $1 \mathrm{mg} / \mathrm{ml})$ for $24 \mathrm{~h}$, cells at a density of 1,000 per group were seeded into a 6-well plate, and cultured for 10 days for the formation of colonies. Then the colonies formed were fixed with $4 \%$ formaldehyde for $10 \mathrm{~min}$, followed by visualization treatment with $0.3 \%$ crystal violet staining for $15 \mathrm{~min}$. After removing excess crystal violet by rinsing the plate with PBS, the visible colonies were counted by ImageJ software, and the rate of colony formation was calculated in each group with the control group set as $100 \%$. This experiment was repeated three times.

Wound healing assay. CRC cells were seeded into a 6-well plate with $2 \mathrm{ml}$ of medium in each well $\left(5 \times 10^{5}\right.$ cells/well). After $24 \mathrm{~h}$, the incubated cells were scraped away vertically in each well with a P200 pipette tip. Under a phase-contrast inverted microscope at a magnification of $\mathrm{x} 100$, for each well three images along the scraped line were randomly selected. Then similarly, after the cells underwent another $24 \mathrm{~h}$ of incubation in the indicated concentrations of EEHDW $(0,0.25,0.5$ and $1 \mathrm{mg} / \mathrm{ml}$ ), a new set of images were captured. By comparing these two groups of images, the reduction in the number of cells within the scraped area indicated the cell migration rate. Image J software was used to analysis the images in this assay. This experiment was repeated three times.

Assessment of cell migration by Transwell assay. Transwell cell culture chambers (cat. no. 3422; Corning Life Sciences, Corning, NY, USA) were used and the Transwell inserts were placed into a 24-well plate where each well contained chemoattractant solution. The cells for migration assay were prepared by being seeded into a 6 -well plate and incubated for $24 \mathrm{~h}$ after treatment with EEHDW $(0,0.125,0.25,0.5$ and $1 \mathrm{mg} / \mathrm{ml})$. The incubated cells were then diluted into a density of $5 \times 10^{4}$ cells

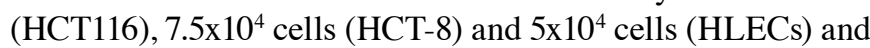
pipetted into the inserts containing suspension solution with $0.2 \mathrm{ml}$ RPMI-1640 medium. After the cells were incubated for $24 \mathrm{~h}$, the upper-side of the polycarbonate membrane was scraped, leaving the underside of the membrane with migrated cells, which were stained with crystal violet for $15 \mathrm{~min}$ at room temperature. To count the number of the migrated cells, three random areas on each membrane were chosen and counted under a phase-contrast microscope (Leica, Germany) at a magnification of $x 200$. This experiment was repeated three times.

ELISA assays. The secretion level of VEGF-C was measured using ELISA kits (cat. no. TAE-577h-c; Tianjin Aoric Bio-Technology Co., Tianjin, China) according to the manufacturer's instructions. The wells in a coated microwell plate were filled with $50 \mu \mathrm{l}$ of each concentration of standard or $25 \mu \mathrm{l}$ test samples, and then the test sample plates were filled with $25 \mu \mathrm{l}$ biotin. All wells were filled with $50 \mu \mathrm{l}$ enzyme conjugation liquid and incubated for $1 \mathrm{~h}$ at $37^{\circ} \mathrm{C}$. After 5 times of washes with washing liquid, TMB1 and TMB2 were added to the wells, and incubation was carried out for $20 \mathrm{~min}$ at room temperature. Finally, the wells were added with stopping liquid and the absorbance was measured at $450 \mathrm{~nm}$. This experiment was repeated eight times. 
Cell cycle assays by flow cytometry. Cell cycle distribution was assessed in the HLECs after treatment with the indicated concentrations of EEHDW (0, 0.125, 0.25 and $0.5 \mathrm{mg} / \mathrm{ml})$. Cell cycle progression was estimated using a Propidium Iodide (PI) kit (cat. no. KGA512; KeyGen Biotech Co., Nanjing, China) with fluorescence-activated cell sorting (ModFitLT version 3.0; Verity Software House, Inc., Topsham, ME, USA) according to the manufacturer's instructions.

Cell apoptosis assays by flow cytometry. A total of $2 \times 10^{5}$ HLECs cells were seeded into 6-plates in $2 \mathrm{ml}$ medium and treated with indicated concentrations of EEHDW $(0,0.125$, 0.25 and $0.5 \mathrm{mg} / \mathrm{ml}$ ) or $5 \mathrm{ng} / \mathrm{ml} \mathrm{VEGF-C} \mathrm{for} 24 \mathrm{~h}$. The apoptosis in HLECs after treatment with EEHDW was estimated using an Annexin V-FITC/PI kit (cat. no. KGA108, KeyGen Biotech Co.) with fluorescence-activated cell sorting caliber (FACSCalibur $^{\mathrm{TM}}$; BD Biosciences, San Jose, CA, USA). The treatment method was carried out according to the manufacturer's instructions.

Tube formation assays. The assay was conducted as previously described (10). Briefly, after treatment with EEHDW (0.125, 0.25 and $0.5 \mathrm{mg} / \mathrm{ml})$ and/or exogenous VEGF-C $(5 \mathrm{ng} / \mathrm{ml})$ for $24 \mathrm{~h}$, HLECs were diluted into a density of $2 \times 10^{5}$ cells in $200 \mu \mathrm{l}$ medium per group, before being seeded into a 1:1 ECMatix (ECM625; Millipore, Billerica, MA, USA) gel (v/v)-coated 48-well plate. The cells then were incubated for $8 \mathrm{~h}$. Then by using a phase-contrast microscope at a magnification of $x 40$, the series of tube-like structures were examined and photographed.

Western blot assays. HCT116, HCT-8 and HLECs cells were seeded at a density of $2.5 \times 10^{5}$ cells/well into 6 -well plates in $2 \mathrm{ml}$ complete medium, and were treated with various concentrations of EEHDW $(0,0.125,0.25,0.5$ and $1 \mathrm{mg} / \mathrm{ml})$ for a total of $24 \mathrm{~h}$ at $37^{\circ} \mathrm{C}$. The treated cells were washed with PBS and scraped off into a tube, then lysed using lysis buffer containing protease and phosphatase inhibitor cocktails on ice for $15 \mathrm{~min}$. Following high-speed centrifugation $(12,000 \mathrm{x} \mathrm{g})$ for $20 \mathrm{~min}$ at $4^{\circ} \mathrm{C}$, supernatant containing the sample proteins was collected. The concentration of proteins was determined using the bicinchoninic acid (BCA) assay (cat. no. 23227; Thermo Fisher Scientific, Inc.), and the total protein concentrations were determined. After separating the total proteins into $50 \mu \mathrm{g}$ and resolving them in 10\% SDS-PAGE gels, electro-blotting was carried out. After this, the separated proteins were subsequently transferred onto NC membranes (cat. no. HATF00010; Millipore, Billerica, MA, USA) which were blocked and probed with primary antibodies: VEGF-C, VEGFR-3 and $\beta$-actin (cat. nos. 2445, 2485, 4967, respectively; dilution 1:1,000; Cell Signaling, Beverly, MA, USA), PI3K, AKT, ERK and STAT3 (cat. nos. 13329-1-AP, 10176-2-AP, 16443-1-AP and 10253-2-AP, respectively; dilution 1:2,000; Proteintech, USA), p-PI3K, p-AKT, p-ERK and cyclin D1 (cat. nos. sc-12929, sc-135650, sc-16982 and sc-753, respectively; dilution 1:1,000; Santa Cruz Biotechnology, Santa Cruz, CA, USA), CDK4, MMP2, MMP9 and p-STAT3 (cat. nos. ab137675, ab37150, ab38898 and ab76315, respectively; dilution 1;1,000; Abcam) overnight at $4^{\circ} \mathrm{C}$. On the second day, the appropriate HRP-conjugated secondary antibody (cat. no. E030120; EarthOx, Millbrae, CA, USA) was added and SuperSignal West Pico Chemiluminescent Substrate was used to detect the signal. Image Lab $^{\text {TM }}$ Software (version 3.0) was used for densitometric analysis/quantification of the western blot (Bio-Rad Laboratories Inc., Hercules, CA, USA).

Statistical analysis. One-way ANOVA and SPSS software (version 18.0; SPSS, Inc., Chicago, IL, USA) were used to analyze all the data in this study. LSD and Dunnet's were used as post-hoc tests. Data are expressed as mean \pm standard deviation (SD). $\mathrm{P}<0.05$ was considered as indicative of a statistically significant result.

\section{Results}

EEHDW inhibits the growth of CRC cell lines. We used MTT assays to determine the effect of EEHDW on the viability of HCT116 and HCT-8 cell lines. After their treatment with EEHDW at $0,0.25,0.5,1.0$ and $2.0 \mathrm{mg} / \mathrm{ml}$ for $24 \mathrm{~h}$, the cell viability was reduced from $100 \%$ (control) to $37.32 \pm 3.08 \%$ ( $2 \mathrm{mg} / \mathrm{ml} \mathrm{EEHDW)} \mathrm{(HCT116)} \mathrm{and} \mathrm{from} 100 \%$ (control) to $43.10 \pm 3.80 \%$ (2 $\mathrm{mg} / \mathrm{ml}$ EEHDW) (HCT-8) (Fig. 1A) $(\mathrm{P}<0.05)$. For verification, we performed a colony formation assay to examine the effect of EEHDW on the survival of CRC cells. As shown in Fig. 1B and C, the survival rates of the EEHDW-treated cells decreased with increasing dose in a dose-dependent manner, relative to the survival rate of the control EEHDW-untreated group.

EEHDW inhibits the migration of CRC cell lines. Wound-healing assays were used to investigate the effect of EEHDW on the migratory ability of CRC cells. During the process, $24 \mathrm{~h}$ after wounding, we observed the migration of the untreated HCT116 and HCT-8 cells (control groups) into the wounded (clear) area of the cell monolayer. Compared with the control group (100\%), the percentages of the wound area in the HCT116 cells after treatment with $0,0.25,0.5$ and $1.0 \mathrm{mg} / \mathrm{ml}$ EEHDW were 51.92 $\pm 5.56,64.55 \pm 6.37,72.38 \pm 4.95$ and $98.43 \pm 7.21 \%$, respectively $(\mathrm{P}<0.05)$; the percentages of the wound area in the HCT- 8 cells were $21.18 \pm 3.14,38.31 \pm 5.24$, $45.89 \pm 5.98$ and $50.91 \pm 6.09 \%$, respectively $(\mathrm{P}<0.05)$ (Fig. 2A and B), which confirmed that the migration rates of both cell lines were significantly inhibited by the EEHDW treatment. We also used a Transwell assay to detect the effect, as shown in Fig. 2C and D, and found that EEHDW significantly inhibited the migration of the CRC cells.

EEHDW downregulates the expression and secretion of $V E G F-C$ in the $C R C$ cell lines. To understand the potential mechanism involved in the EEHDW-mediated inhibition of CRC cell migration, the expression and secretion levels of VEGF-C were assessed in the CRC cells following treatment with $0,0.25,0.5$ and $1.0 \mathrm{mg} / \mathrm{ml}$ EEHDW by western blot analysis and ELISA assay. We found that EEHDW significantly inhibited the expression (Fig. 3A and B) and secretion (Fig. 3C) of VEGF-C $(\mathrm{P}=0.00)$.

EEHDW reduces the growth of VEGF-C-stimulated HLECs. The viability of HLECs was increased to $106.45 \pm 6.59 \%$ at $24 \mathrm{~h}$ after VEGF-C stimulation relative to the viability of 

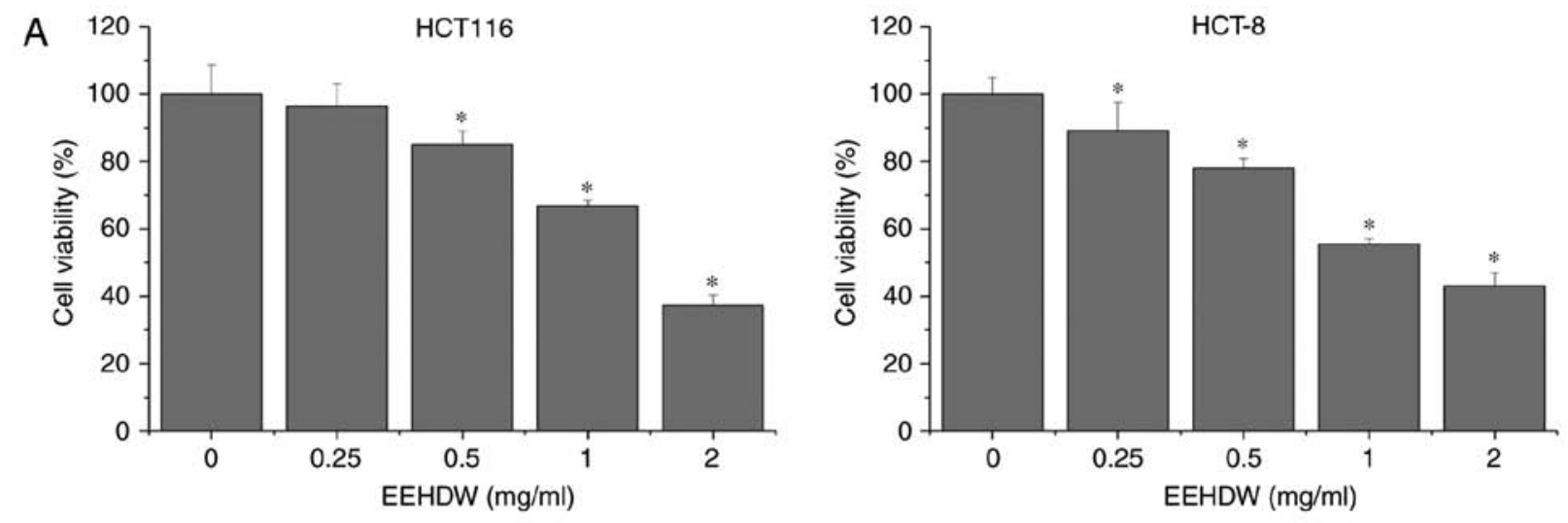

B
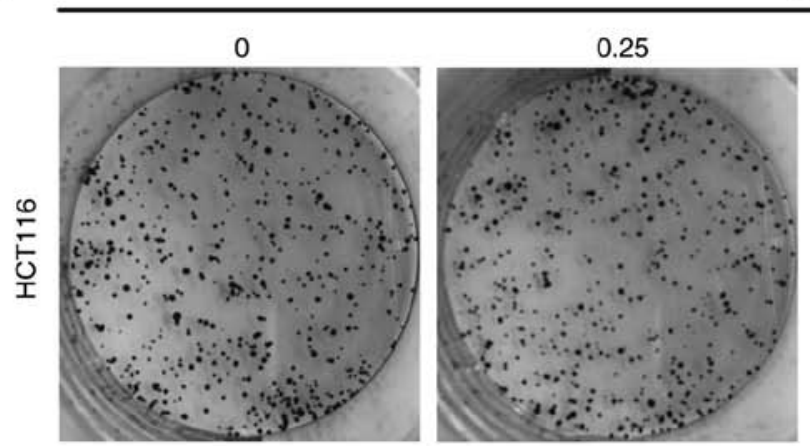

$\operatorname{EEHDW}(\mathrm{mg} / \mathrm{ml})$
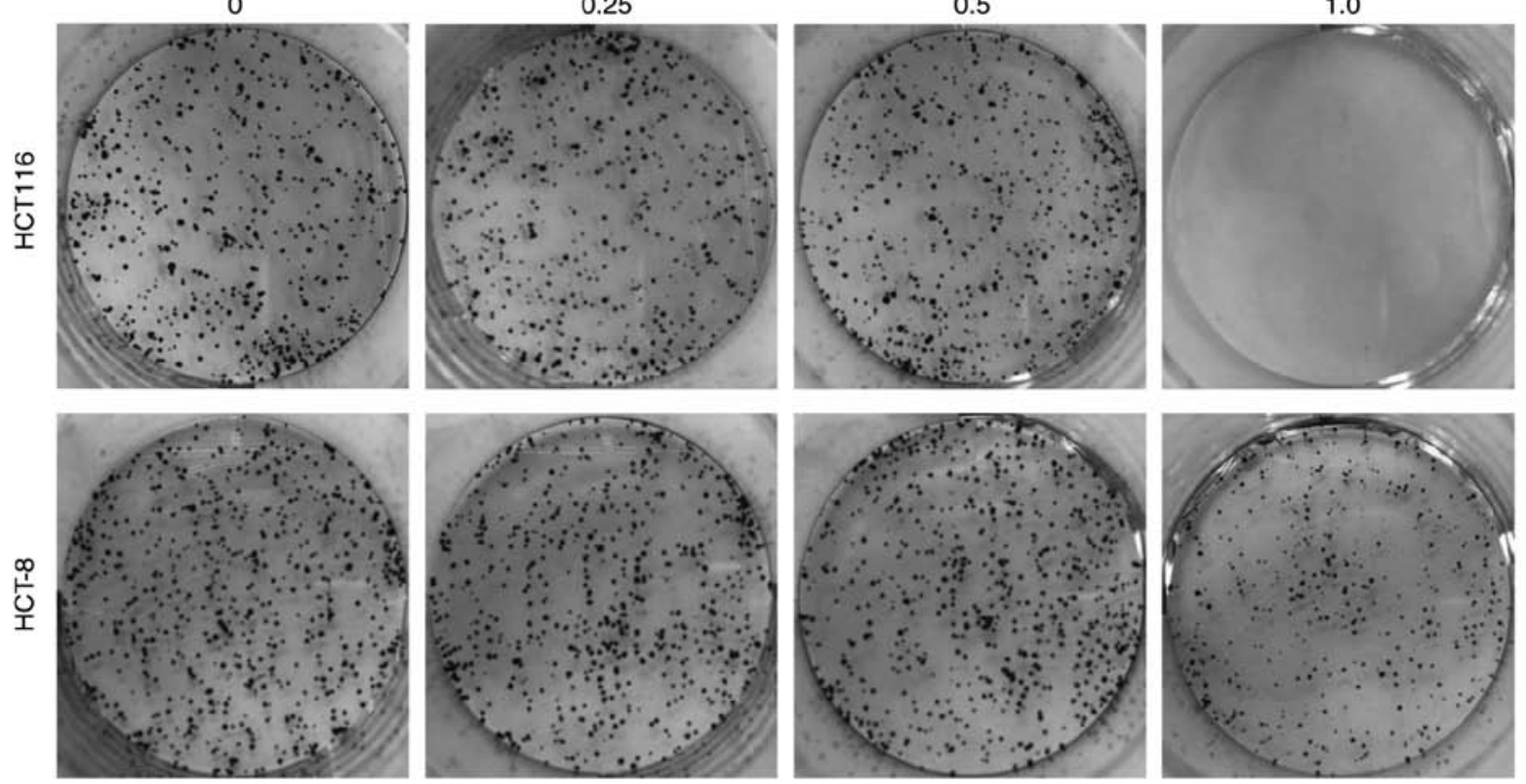

C
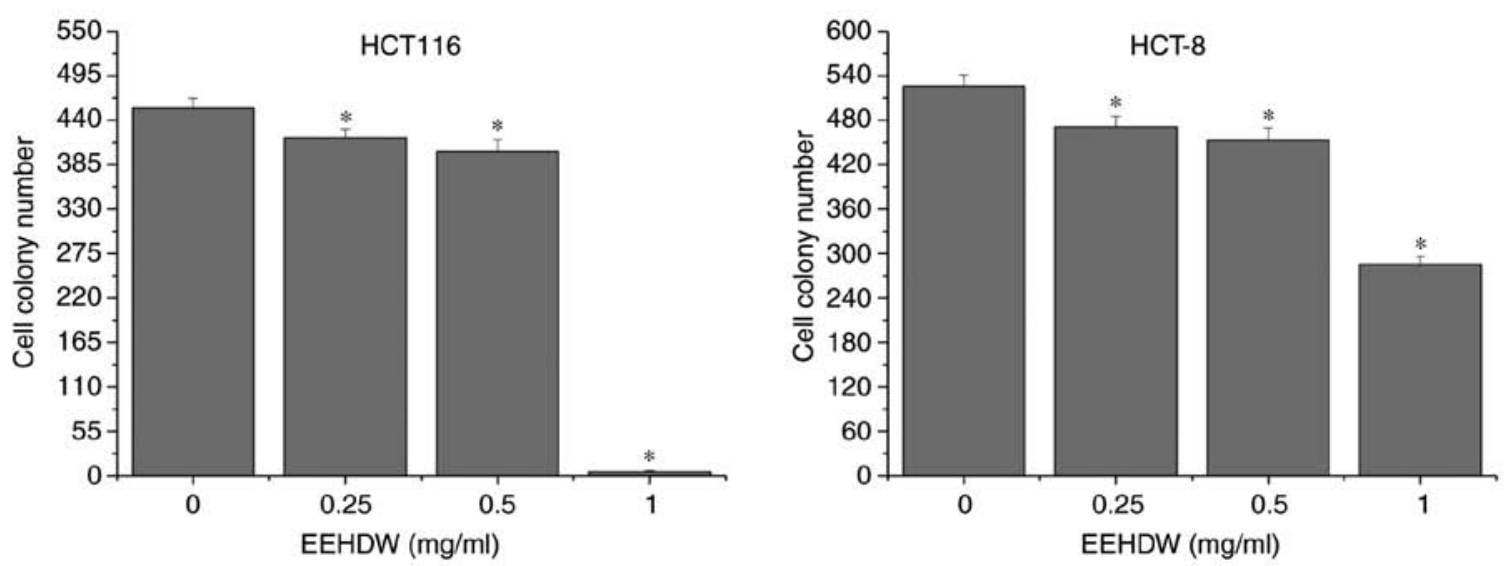

Figure 1. Effect of EEHDW on the growth of HCT116 and HCT-8 cells. (A) Cell viability of CRC HCT116 and HCT-8 cell lines was assessed by MTT assay following treatment with $0,0.25,0.5,1.0$ and $2.0 \mathrm{mg} / \mathrm{ml}$ EEHDW. (B) Cell growth ability was assessed by colony formation assay. (C) Quantitative analysis of the colony formation assay. "P<0.05 vs. the control group. CRC, colorectal cancer; HDW, Hedyotis diffusa Willd.; EEHDW, ethanol extract of HDW.

the control cells $(\mathrm{P}<0.05)$, whereas viability was significantly decreased from $94.87 \pm 2.91$ to $45.64 \pm 2.46 \%$ after EEHDW treatment (from 0.125 to $1.0 \mathrm{mg} / \mathrm{ml}$ ) (Fig. 4A). Using a colony formation assay, we found that after VEGF-C stimulation, the survival rate of the HLECs was increased. After EEHDW treatment, the survival rate decreased dose-dependently relative to the rate in the untreated control cells (Fig. 4B). Cell colony formation assay indicates the cell survival ability; therefore, in our study, this data only confirmed that EEHDW decreased the ability of survival. We also performed cell 

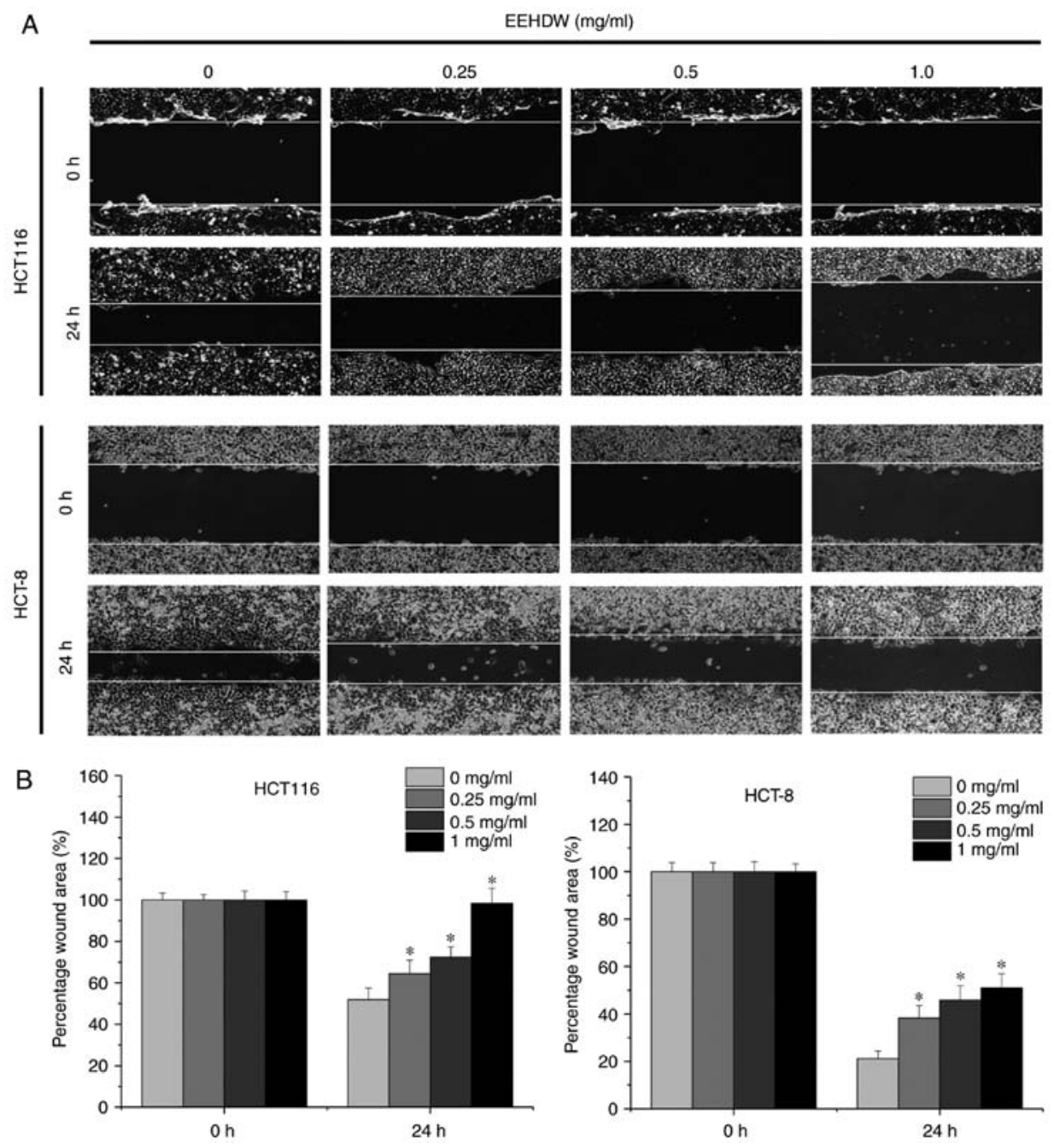

C

$\operatorname{EEHDW}(\mathrm{mg} / \mathrm{ml})$
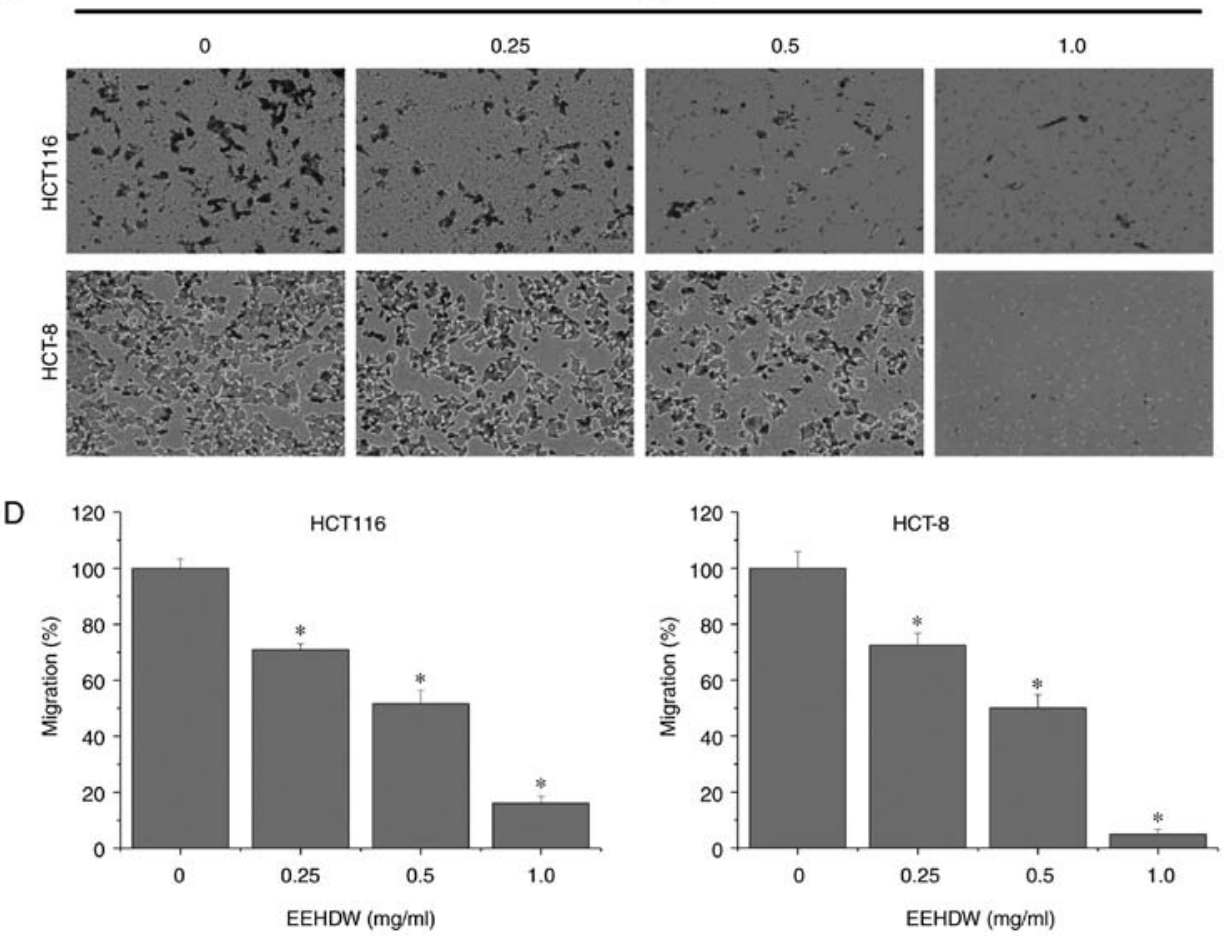

Figure 2. Effect of EEHDW on the migration of HCT116 and HCT-8 cells. (A) Migration ability in the CRC HCT-116 and HCT-8 cells following treatment with $0,0.25,0.5$ and $1.0 \mathrm{mg} / \mathrm{ml} \mathrm{EEHDW}$ was detected by wound healing assays (magnification, $\mathrm{x} 100)$. (B) Quantitative analysis of the wound healing assays. "P $<0.05$ vs. the control group. (C) Migration ability in the HCT116 and HCT-8 cells was detected by Transwell assays (x200). (D) Quantitative analysis of the Transwell assays. "P<0.05 vs. the control group. CRC, colorectal cancer; HDW, Hedyotis diffusa Willd.; EEHDW, ethanol extract of HDW. 
A
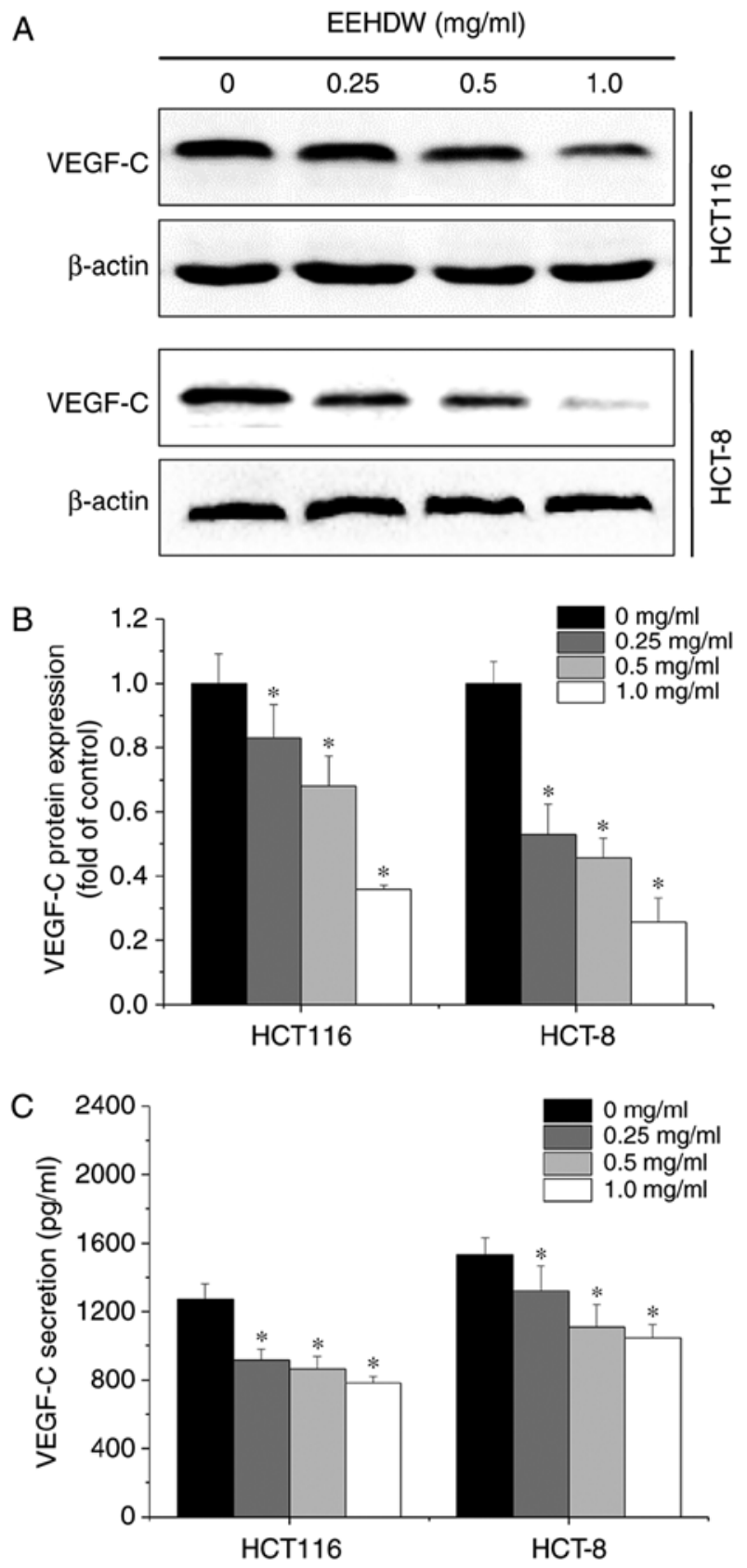

Figure 3. Effect of EEHDW on the expression and secretion of VEGF-C in CRC HCT116 and HCT-8 cells. (A) The expression of VEGF-C in HCT116 and HCT- 8 cells following treatment with $0,0.25,0.5$ and $1.0 \mathrm{mg} / \mathrm{ml} \mathrm{EEHDW}$ was determined by western blot assay. $\beta$-actin was used as an internal control. (B) The band densities of the western blot in (A) were quantitatively analyzed. ${ }^{*} \mathrm{P}<0.05$ vs. the control group. (C) The secretion of VEGF-C was determined by ELISA. ${ }^{*} \mathrm{P}<0.05$ vs. the control group. VEGF-C, vascular endothelial growth factor $\mathrm{C} ; \mathrm{CRC}$, colorectal cancer; HDW, Hedyotis diffusa Willd.; EEHDW, ethanol extract of HDW.

cycle assay to detect the effect of EEHDW on cell cycle distribution. However, the distribution of cells in the G0/G1, $\mathrm{S}, \mathrm{G} 2 / \mathrm{M}$ phases following treatment with $0,0.125,0.25$ and $0.5 \mathrm{mg} / \mathrm{ml}$ EEHDW had no statistically significant difference (Fig. 4C). Thus, the effect of EEHDW on the significant reduction in cell proliferation is influenced by the changes in cell survival ability. Moreover, we used Annexin V/PI staining and fluorescence-activated cell sorting analysis to investigate the effect of EEHDW on the apoptosis of HLECs after VEGF-C stimulation. The results showed that after EEHDW treatment at $0.125,0.25$ and $0.5 \mathrm{mg} / \mathrm{ml}$, there were no significant differences in the percentage of cells undergoing apoptosis in the EEHDW-treated groups and the control group without EEHDW treatment (Fig. 4D). These results indicated that EEHDW reduced the growth of VEGF-C-stimulated HLECs but had no proapoptotic effect in the dose range of 0.125 to $0.5 \mathrm{mg} / \mathrm{ml}$ EEHDW.

EEHDW inhibits the migration and tube formation of $V E G F$-C-stimulated HLECs. The migration abilities of HLECs after VEGF-C stimulation were enhanced, whereas this enhanced effect was significantly attenuated by treatment with $0.125,0.25$ and $0.5 \mathrm{mg} / \mathrm{ml}$ of EEHDW (Fig. 5). Similarly, the rate of tube formation of HLECs significantly increased with exogenous VEGF-C stimulation, relative to the rate in the control cells without VEGF-C treatment, whereas the rate of tube formation of HLECs was significantly decreased after treatment with $0.125,0.25$ and $0.5 \mathrm{mg} / \mathrm{ml}$ of EEHDW (Fig. 6).

EEHDW suppresses the expression of MMP2, MMP9, cyclin D1 and CDK4 in VEGF-C-stimulated HLECs. During cancer metastasis, matrix metalloproteinase (MMP)2, MMP9, cyclin D1 and cyclin-dependent kinase 4 (CDK4) are important factors for cell proliferation and migration $(23,24)$. Therefore, we detected the expression of MMP2, MMP9, cyclin D1 and CDK4 after treatment with $0.125,0.25$ and $0.5 \mathrm{mg} / \mathrm{ml}$ of EEHDW. As shown in Fig. 7, we found that expression levels of MMP2, MMP9, cyclin D1 and CDK4 were upregulated after VEGF-C stimulation but downregulated after EEHDW treatment.

EEHDW suppresses multiple signaling pathways in the VEGF-C-stimulated HLECs. As important as VEGF-C is to the proliferation and migration of HLECs $(11,13)$, the expression of VEGFR-3 is also closely related to these processes. Additionally, multiple signaling pathways, including the PI3K/AKT, ERK and STAT3 pathways, can be upregulated as well as some factors, such as MMPs, cyclins, and relevant dependent kinases (14). To further investigate the anti-lymphangiogenesis effects of EEHDW, we examined the expression of related proteins after EEHDW treatment. We found that the expression level of VEGFR3 increased by $1.35 \pm 0.03$ times after VEGF-C stimulation, whereas the level decreased from $1.35 \pm 0.03$ times to $0.72 \pm 0.02$ times with EEHDW treatment. The expression levels p-PI3K/PI3K,p-AKT/AKT, p-ERK/ERK and $\mathrm{p}$-STAT3/STAT3 were increased by $1.31 \pm 0.03,1.11 \pm 0.05$, $1.81 \pm 0.07$ and $1.35 \pm 0.02$ times, respectively, after VEGF-C stimulation, whereas the levels decreased to $0.86 \pm 0.05$, $0.73 \pm 0.04,0.72 \pm 0.05$ and $0.33 \pm 0.01$ times, respectively, following EEHDW treatment (Fig. 8).

\section{Discussion}

Many colorectal cancer (CRC) patients succumb to disease due to tumor metastasis (3). Many cell processes, including tumor cell migration, angiogenesis and lymph angiogenesis, promote such tumor metastasis, and a key process is lymph angiogenesis $(25,26)$. Preclinical evidence suggests that the spread of 


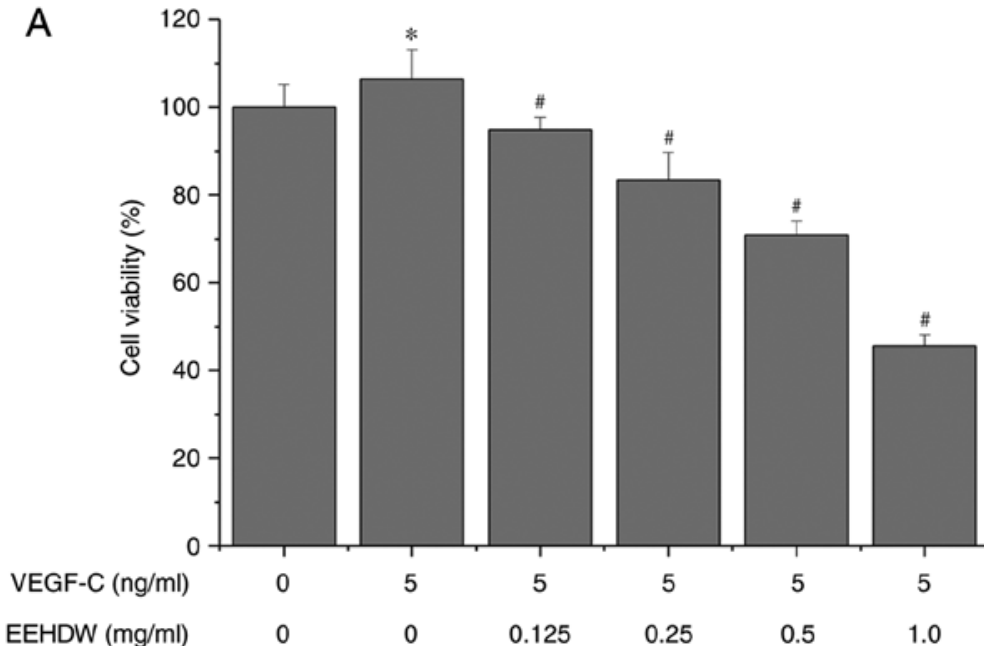

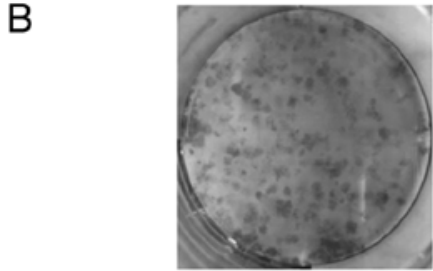

VEGF-C (ng/ml)

EEHDW $(\mathrm{mg} / \mathrm{ml})$

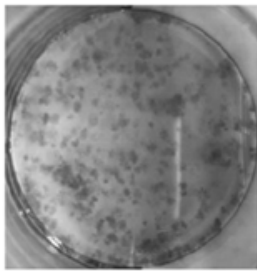

5

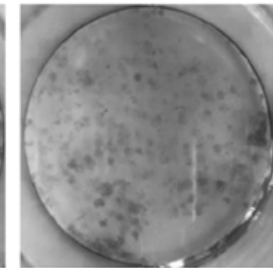

5

0.125

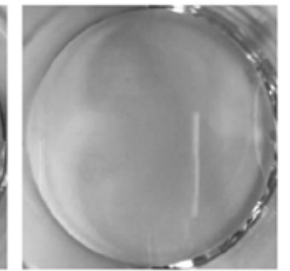

5

0.25

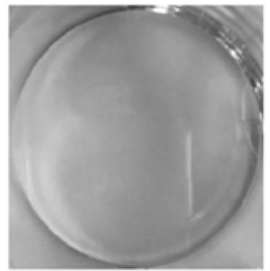

5

0.5

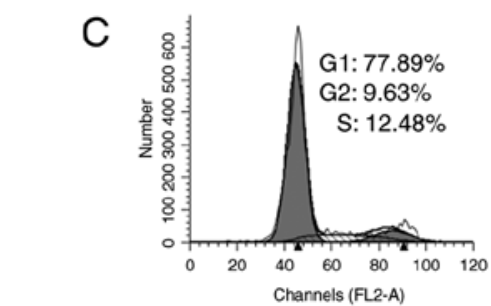

$\operatorname{EEHDW}(\mathrm{mg} / \mathrm{ml})$

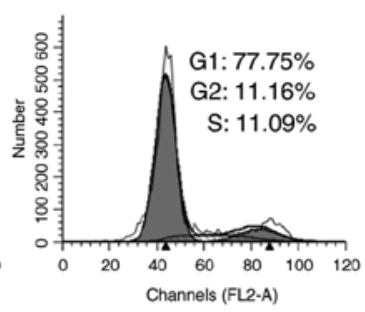

0.125

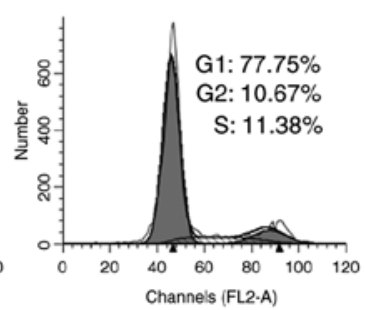

0.25

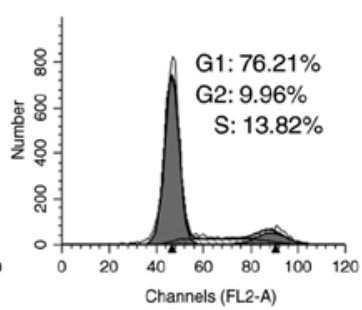

0.5

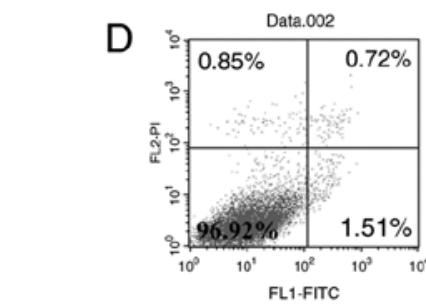

VEGF-C (ng/ml)

EEHDW ( $\mathrm{mg} / \mathrm{ml})$

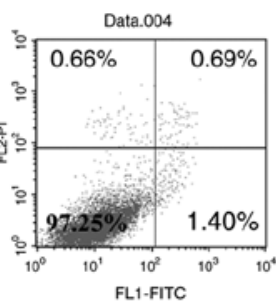

5

0

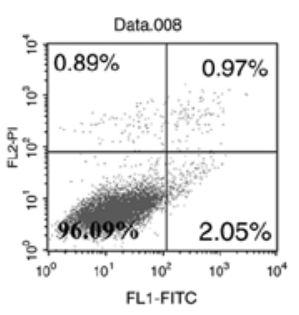

5

0.125

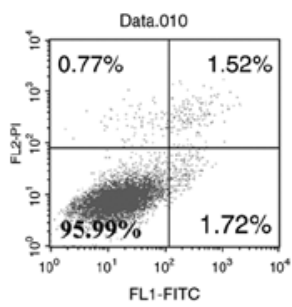

5

0.25

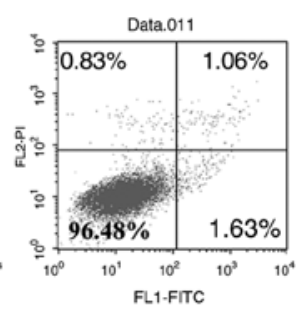

5

0.5

Figure 4. Effect of EEHDW on the growth of VEGF-C-stimulated HLECs. (A) Cell viability in the VEGF-C (5 ng/ml)-stimulated HLECs following treatment with $0,0.125,0.25,0.5$ and $1.0 \mathrm{mg} / \mathrm{ml}$ EEHDW was determined by MTT assay. ${ }^{~} \mathrm{P}<0.05$ vs. the control group; $\mathrm{P}<0.05$ vs. the VEGF-C-stimulated group. (B) Cell growth ability was measured in VEGF-C-stimulated HLECs following treatment with $0,0.125,0.25$ and $0.5 \mathrm{mg} / \mathrm{ml}$ EEHDW by colony formation assay. (C) Cell cycle distribution in VEGF-C-stimulated HLECs after treatment with $0,0.125,0.25$ and $0.5 \mathrm{mg} / \mathrm{ml}$ EEHDW was detected by PI staining with flow cytometric analysis. (D) Apoptosis in VEGF-C-stimulated HLECs after treatment with VEGF-C and EEHDW was detected by Annexin V-FITC/PI staining with flow cytometry analysis. VEGF-C, vascular endothelial growth factor C; HLECs, human lymphatic endothelial cells; HDW, Hedyotis diffusa Willd.; EEHDW, ethanol extract of HDW.

cancer can be blocked by the inhibition of cancer-mediated lymphangiogenesis (27). Recently, many studies have provided new clues to the development of lymphatic vessels and the mechanisms underlying lymph node metastasis.

Reportedly, VEGF-C, which is a lymphangiogenic marker, determines the development of lymphangiogenesis and lymph metastasis (28). Furthermore, the role of VEGF-C is important in many human cancers, including CRC and lung cancer (29). Previous research (10) suggest that lymphatic vessel growth and metastasis can be promoted by the complex of VEGF-C and VEGFR3, abundantly expressed in human lymphatic endothelial cells (HLECs). 
A

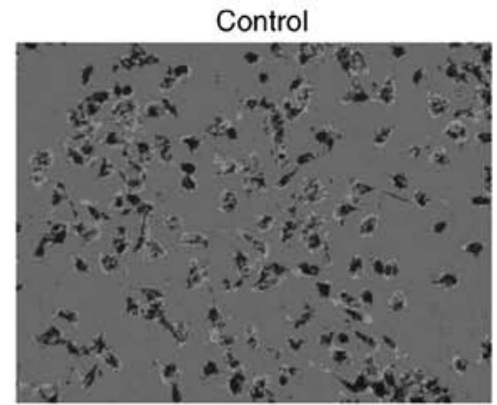

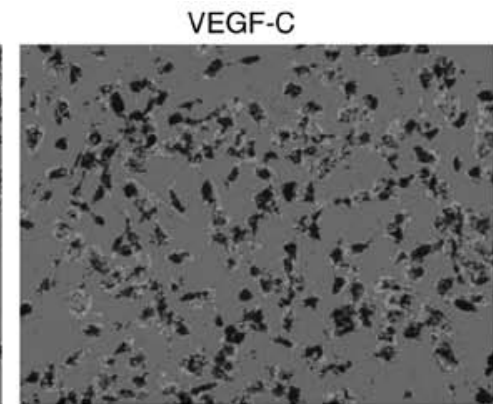

VEGF-C+EEHDW $0.5 \mathrm{mg} / \mathrm{ml}$

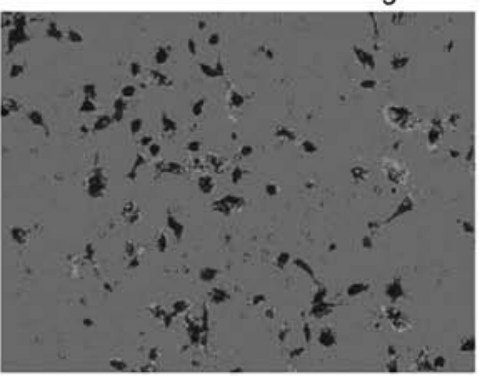

VEGF-C+EEHDW $0.25 \mathrm{mg} / \mathrm{ml}$
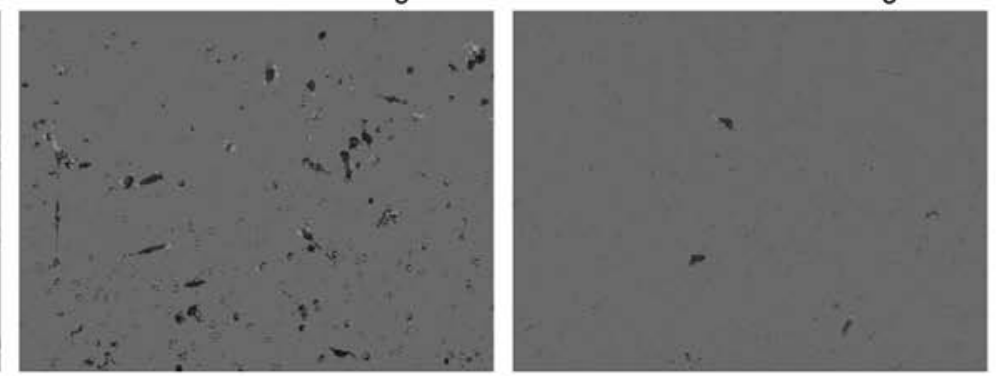

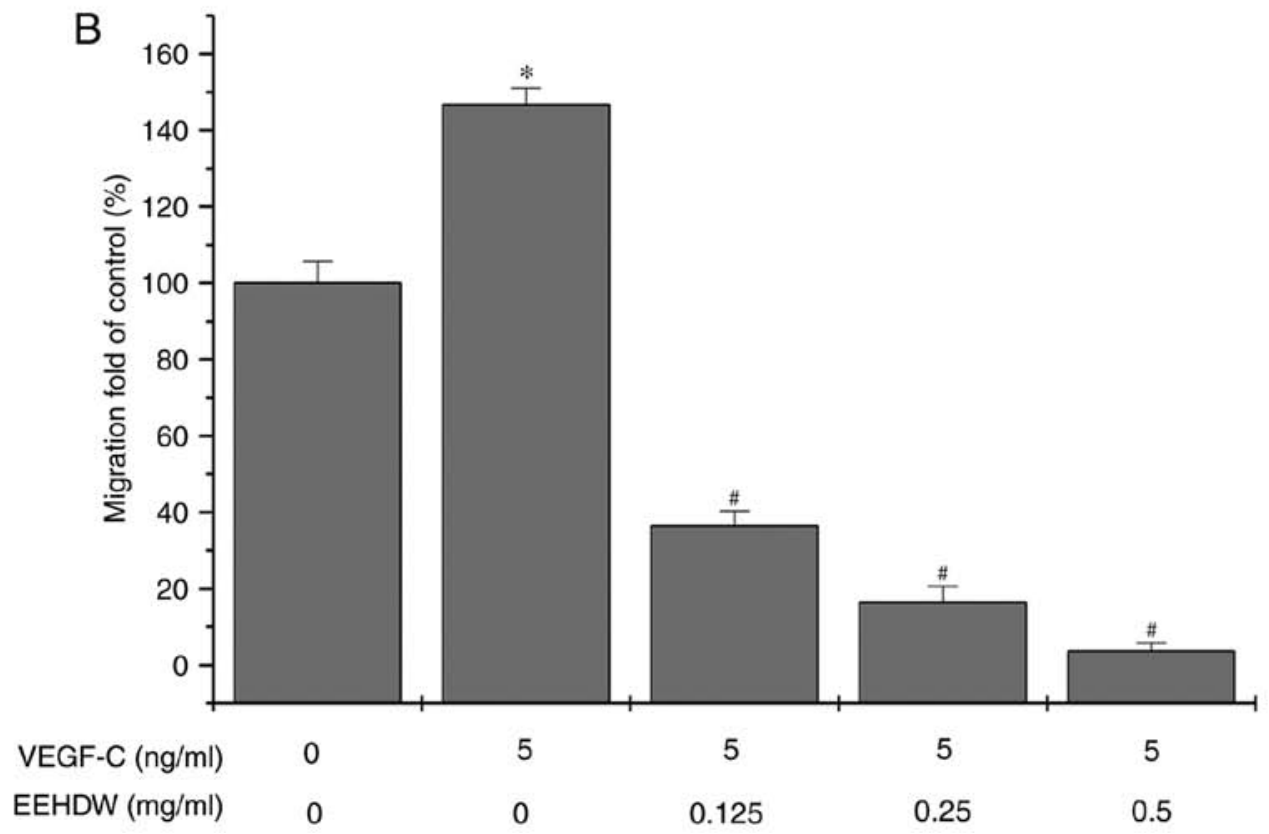

Figure 5. Effect of EEHDW on the migration ability of VEGF-C-stimulated HLECs. (A) Migration ability in HLECs cells after treatment with VEGF-C $(5 \mathrm{ng} / \mathrm{ml})$ and EEHDW $(0,0.125,0.25$ and $0.5 \mathrm{mg} / \mathrm{ml})$ was detected by Transwell assays (x200). (B) Quantitative analysis of the Transwell assay. "P<0.05 vs. the control group; "P<0.05 vs. the VEGF-C-stimulated group. VEGF-C, vascular endothelial growth factor C; HLECs, human lymphatic endothelial cells; HDW, Hedyotis diffusa Willd.; EEHDW, ethanol extract of HDW.

A new therapeutic strategy for CRC is the targeting of lymphangiogenesis and VEGF-C. However, in clinical practice, there are many disadvantages, including drug resistance, metastatsis and tumor recurrence. Recently, cancer treatment using medicinal herbs has drawn increasing attention due to their significant efficacy and few side effects. Hedyotis diffusa Willd. (HDW), an annual herb, has long been used in clinical practice for its anti-inflammatory, anti-oxidant and anticancer effects, and previous studies of our research group found that an ethanol extract of HDW (EEHDW) inhibited proliferation, migration, invasion and promoted apoptosis in vivo and inhibited CRC growth in vivo via inhibition of SHH-mediated tumor angiogenesis $(10,18,30)$, and other scholars have also studied the toxicological safety of HDW (31). We also conducted animal experiments to evaluate whether EEHDW is toxic and has adverse side effects on animal body weight, intestinal tissue, liver and other organs. The results demonstrated that EEHDW showed no toxicity and side effects in regards to animal body weight, intestinal tissue, liver and other organs compared with the control group (unpublished data).

In the present study, it was verified that EEHDW could reduce viability, survival ability, and migration in CRC cell lines, which indicated the significant capability of EEHDW in regards to anti-metastasis (Figs. 1 and 2). To explain the 
A

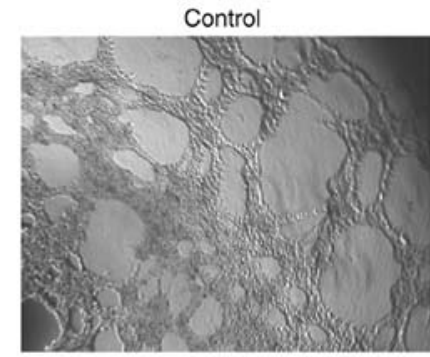

VEGF-C

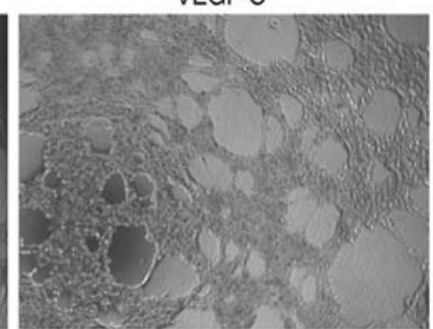

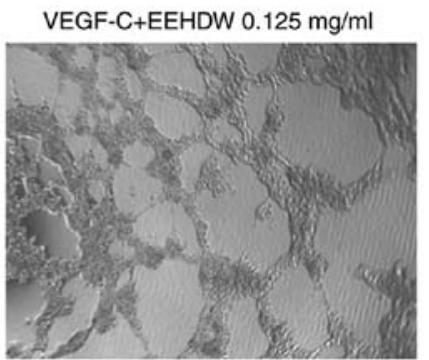

VEGF-C+EEHDW $0.25 \mathrm{mg} / \mathrm{ml}$

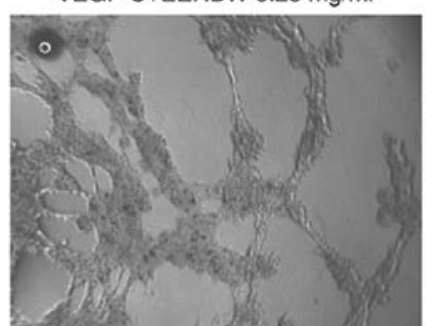

VEGF-C+EEHDW $0.5 \mathrm{mg} / \mathrm{ml}$

B

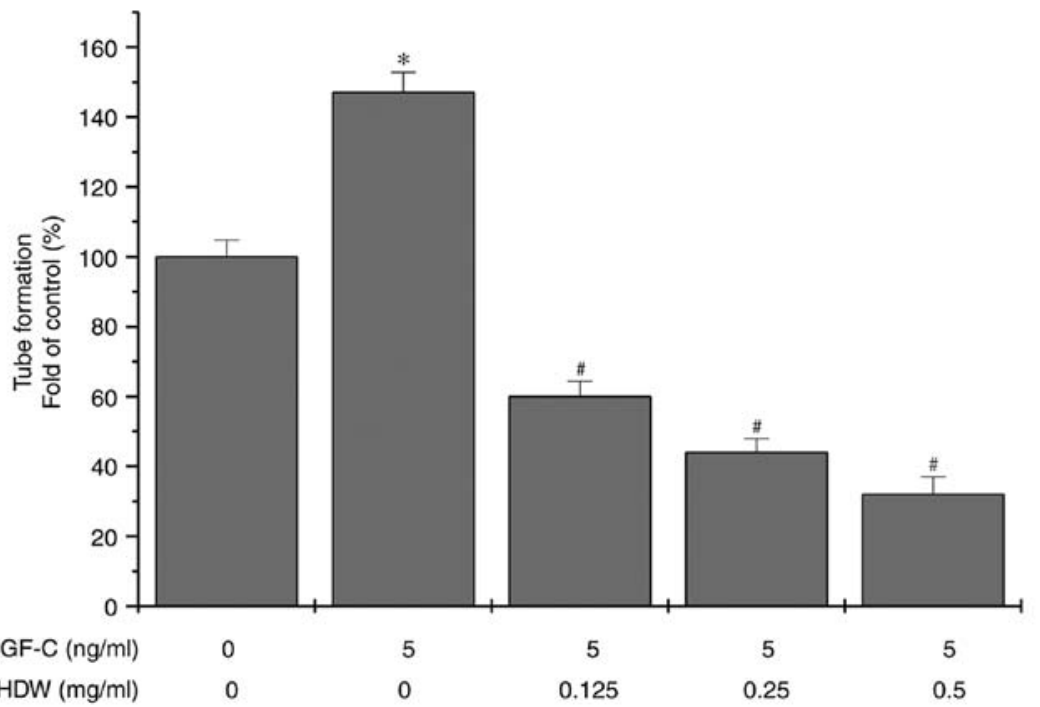

Figure 6. Effect of EEHDW on the tube formation of VEGF-C-stimulated HLECs. (A) Tube formation in HLECs cells after treatment with VEGF-C (5 ng/ml) and EEHDW $(0,0.125,0.25$ and $0.5 \mathrm{mg} / \mathrm{ml})$ was detected by tube formation assays (x40). (B) Quantitative analysis of the tube formation assay. "P<0.05 vs. the control group; "P<0.05 vs. the VEGF-C-stimulated group. VEGF-C, vascular endothelial growth factor C; HLECs, human lymphatic endothelial cells; HDW, Hedyotis diffusa Willd.; EEHDW, ethanol extract of HDW.
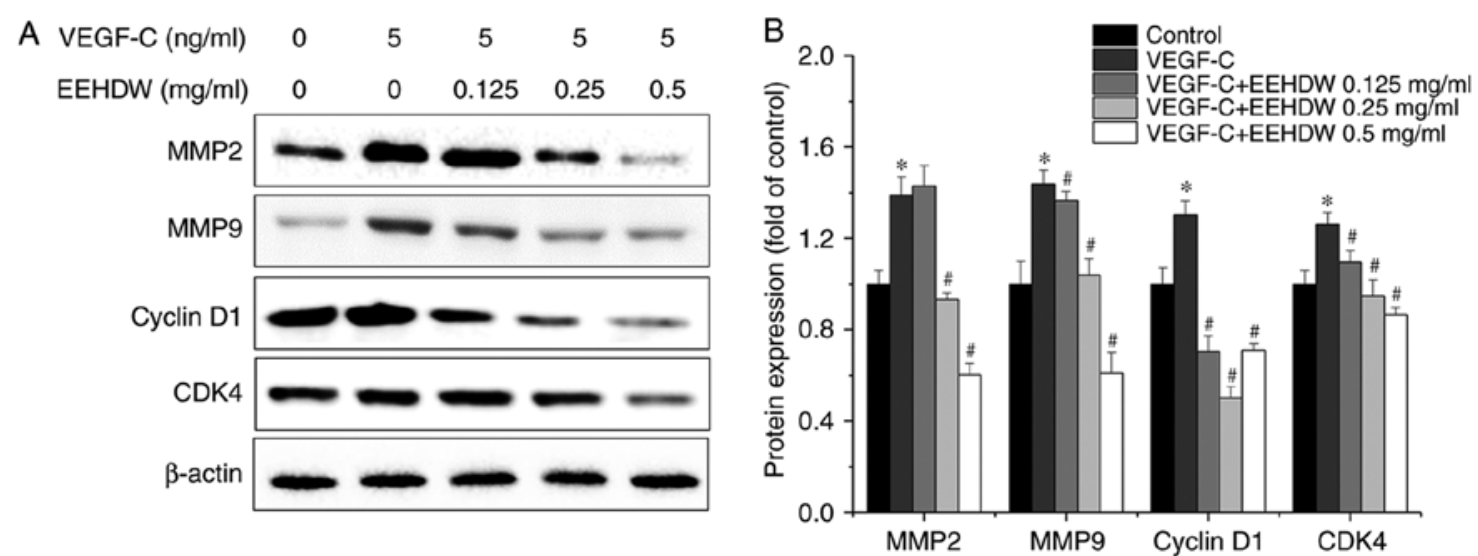

Figure 7. Effect of EEHDW on the expression of MMP2, MMP9, cyclin D1 and CDK4 in VEGF-C (5 ng/ml)-stimulated HLECs. (A) Expression levels of MMP2, MMP9, cyclin D1 and CDK4 in HLECs after treatment with VEGF-C $(5 \mathrm{ng} / \mathrm{ml})$ and EEHDW $(0,0.125,0.25 \mathrm{and} 0.5 \mathrm{mg} / \mathrm{ml})$ were determined by western blot analysis. $\beta$-actin was used as an internal control. (B) Quantitative analysis of the western blot in (A). ${ }^{*} \mathrm{P}<0.05$ vs. the control group; ${ }^{\#} \mathrm{P}<0.05$ vs. the VEGF-C-stimulated group. MMP, matrix metalloproteinase; CDK4, cyclin-dependent kinase 4; VEGF-C, vascular endothelial growth factor C; HLECs, human lymphatic endothelial cells; HDW, Hedyotis diffusa Willd.; EEHDW, ethanol extract of HDW. 
A

\begin{tabular}{|c|c|c|c|c|c|}
\hline VEGF-C (ng/ml) & 0 & 5 & 5 & 5 & 5 \\
\hline EEHDW $(\mathrm{mg} / \mathrm{ml})$ & 0 & 0 & 0.125 & 0.25 & 0.5 \\
\hline VEGFR3 & 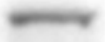 & $=$ & $=$ & $=$ & $=$ \\
\hline
\end{tabular}
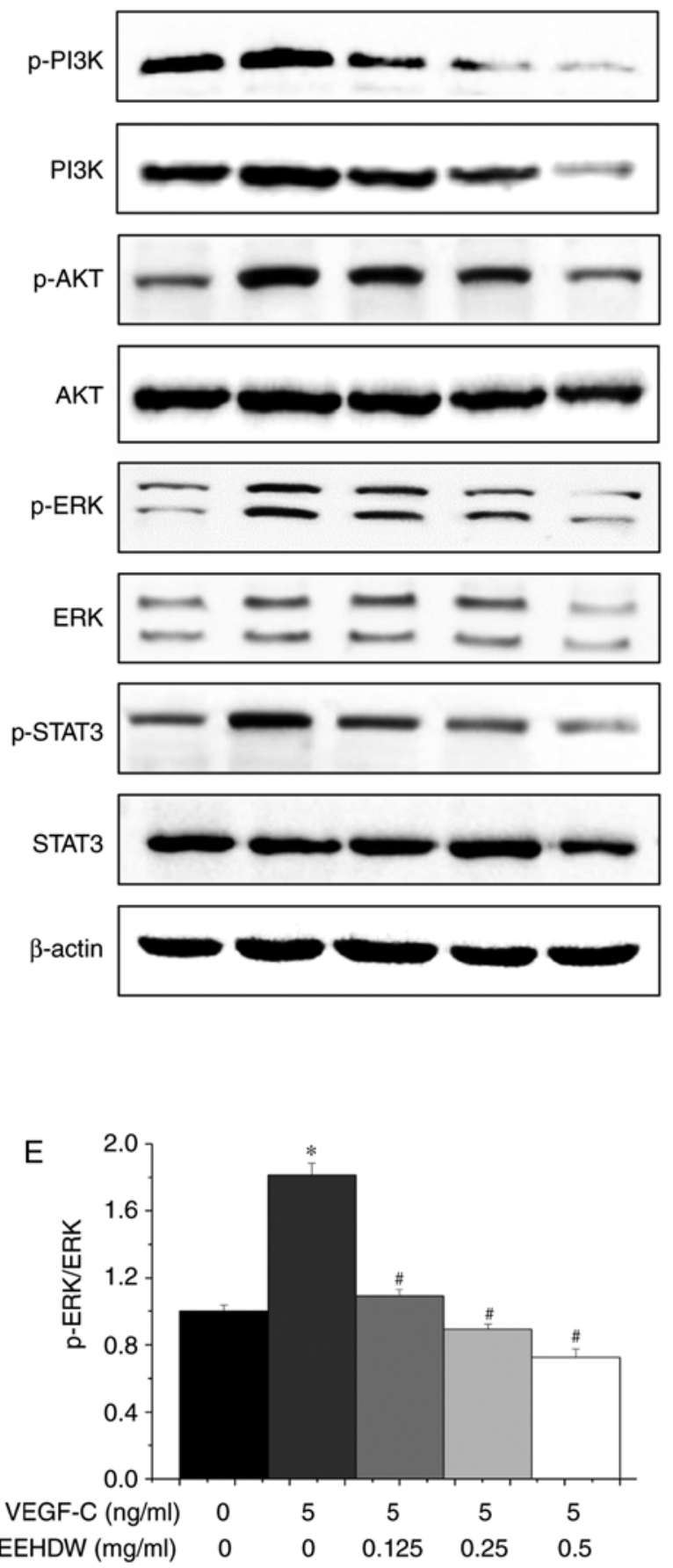
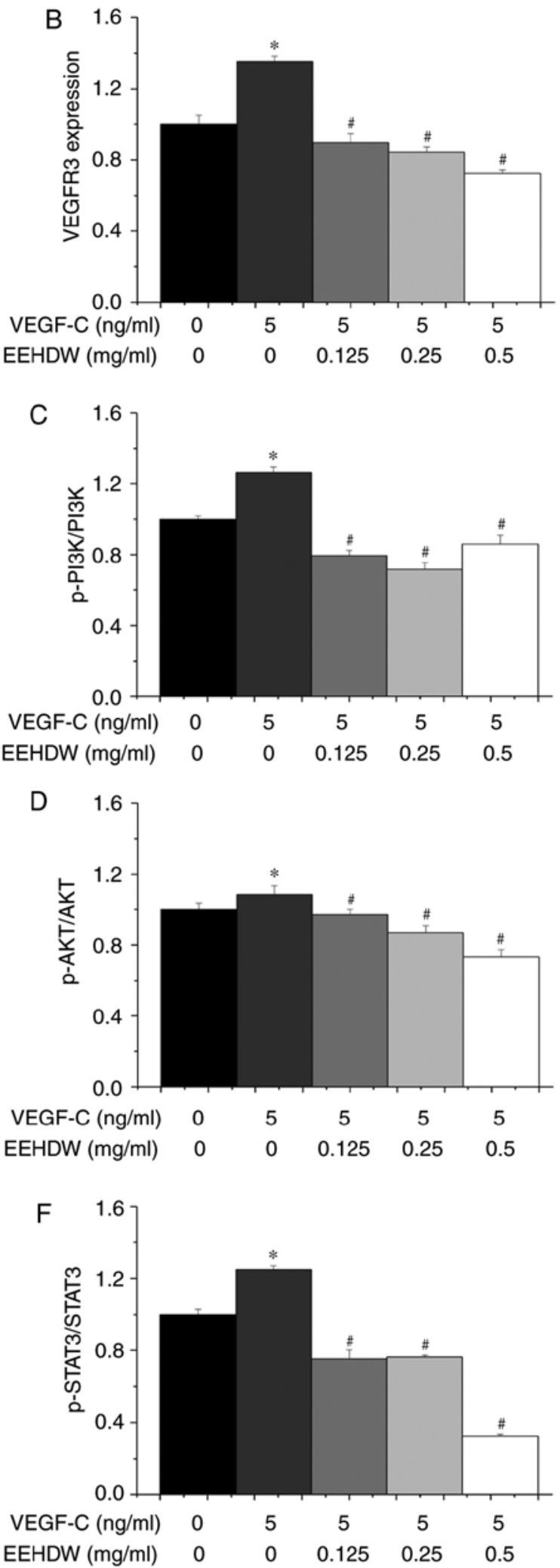

Figure 8. Effect of EEHDW on multiple signaling pathways in VEGF-C-stimulated HLECs. (A) Expression levels of VEGFR3, PI3K, p-PI3K, AKT, p-AKT, ERK, p-ERK, STAT3 and p-STAT3 in HLECs after treatment with VEGF-C (5 ng/ml) and EEHDW $(0,0.125,0.25$ and $0.5 \mathrm{mg} / \mathrm{ml})$ were determined by western blot analysis. $\beta$-actin was used as an internal control. (B-F) Quantitative analyses of the western blot in (A). *P<0.05 vs. the control group; ${ }^{\prime} \mathrm{P}<0.05$ vs. the VEGF-C-stimulated group. VEGF-C, vascular endothelial growth factor C; HLECs, human lymphatic endothelial cells; HDW, Hedyotis diffusa Willd.; EEHDW, ethanol extract of HDW.

mechanism further, we investigated VEGF-C expression and secretion levels in CRC cells. The results showed that EEHDW significantly downregulated VEGF-C expression and secretion (Fig. 3), an indication that a potential mechanism of the anti-metastatic effects of EEHDW may lie in the inhibition of lymphangiogenesis-related VEGF-C expression. 
Since CRC-secreted VEGF-C can promote the formation of lymphatic vessels in HLECs, we established an in vitro model by using exogenous VEGF-C to stimulate HLECs. We found that the viability of the cells and their ability to migrate and form tubes were significantly enhanced after stimulation with $5 \mathrm{ng} / \mathrm{ml}$ of exogenous VEGF-C (Figs. 4 and 5). In contrary, these cell behaviors were attenuated after EEHDW treatment. Yet, these effects were not the result of cell apoptosis, as we showed that EEHDW did not affect apoptosis in HLECs (Fig. 4D). The present study also showed that EEHDW did not affect the cell cycle distribution of HLECs. Additionally, the expression of VEGFR-3, a cognate receptor to VEGF-C, in HLECs was increased after stimulation by exogenous VEGF-C but was notably downregulated by EEHDW treatment.

In addition, various downstream transcription factors (e.g. those in cancer) can be activated by VEGF-C/VEGFR-3. We found that EEHDW prominently inhibited the expression of MMP2, MMP9, cyclin D1 and CDK4 (Fig. 7). MMP2 and MMP9 are two important factors involved in cell migration, whereas exogenous VEGF-C stimulation increased their expression. In tumor tissue, injury to the extracellular matrix can be caused by the overexpression of MMP2 and MMP9 finally leading to the migration of HLECs (32). Previously, EEHDW has been shown to prominently downregulate the expression of cyclin D1 and CDK4, two key factors in cell proliferation, and overexpression of the cyclin D1/CDK4 complex enhanced cell proliferation (33). Overall, these results show that the suppressive effect of EEHDW on lymph angiogenesis via downregulation of VEGF-C may be one of the molecular-level mechanisms that explains how EEHDW inhibits cell metastasis in CRC. In a word, our objective of the present study was to evaluate whether EEHDW can inhibit VEGF-C-mediated lymphangiogenesis in CRC. The results showed that the VEGF-C-stimulated cell migration and tube formation ability were attenuated by EEHDW, and the VEGF-C-stimulated relevant protein expression was also attenuated by EEHDW. All of these results support our final conclusion that EEHDW can inhibit VEGF-C-mediated lymphangiogenesis in CRC. It is universally acknowledged that VEGF-C is currently recognized as the strongest factor involved in lymphangiogenesis and its receptor is VEGFR3. Thus, only after the combination of VEGF-C and VEGFR3 can the corresponding biological effects occur (11-13). This accepted theory does not need to be verified again in this study. But to further strengthen our theory, it may be appropriate to address the mimicking assays, such as, conducting RNA interference assay using siRNA for VEGFR3 in HLEC cells, and analyze the downstream signaling molecules. Thus, this is considered as a limitation of the present study and future research is warranted.

In addition, the VEGF-C/VEGFR3 pathway can activate its downstream pathways, including the PI3K/AKT, ERK, and STAT3 pathways $(34,35)$. PI3K, a key factor during many cellular processes, can mediate signals from receptor tyrosine kinases. Then, AKT is phosphorylated and further activates downstream molecules, consequently regulating cell growth and gene transcription. The PI3K/AKT signaling pathway plays a key role in cell survival. As demonstrated by our results, the protein expression ratios of $\mathrm{p}-\mathrm{PI} 3 \mathrm{~K} / \mathrm{PI} 3 \mathrm{~K}$, and $\mathrm{p}$-AKT/AKT were increased by VEGF-C but decreased by EEHDW, which indicated that the PI3K/AKT pathway is involved in lymphangiogenesis. Additionally, ERK, part of the MAPK pathway, has been identified as a cell growth-related pathway. In the present study, we found that after stimulation with VEGF-C, the expression ratio of p-ERK/ERK was increased, whereas after treatment with EEHDW, the protein expression ratio was decreased (Fig. 8). Additionally, in cutaneous melanoma, interaction between the PI3K/AKT and ERK pathways has been previously demonstrated $(36,37)$.

Importantly, these study findings suggest that activation of the PI3K/AKT, ERK, and STAT3 pathways occur in parallel, with a wide range of evidence on their interconnectivity. Between these three pathways, multiple crosstalk points have been detected and activated coordinately, which determine the fate of cells. Not surprisingly, both negative and positive influences of the PI3K/AKT, ERK, and STAT3 pathways have been identified during different stages of signal propagation. Our findings indicate that the PI3K/AKT, ERK, and STAT3 pathways could provide a promising target for cancer therapy (Fig. 8).

In conclusion, EEHDW inhibited VEGF-C-mediated lymphangiogenesis in CRC by the suppression of multiple (PI3K/AKT, ERK, STAT3) signaling pathways and appears to be a promising multi-potent anticancer agent for the clinical treatment of CRC.

\section{Acknowledgements}

Not applicable.

\section{Funding}

This study was sponsored by the Project of Funding for the Training of Young and Middle-aged 'Backbone' Personnel of Fujian Provincial Health and Family Planning Commission (Fujian, China; grant no. 2016-ZQN-67), and Scientific Research Foundation of Traditional Chinese Medicine of Fujian Provincial Health and Family Planning Commission (Fujian, China; grant no. 2017FJZYZY203).

\section{Availability of data and materials}

All data generated or analyzed during this study are included in this published article.

\section{Authors' contributions}

HL and JL conceived and designed the experiments. HY, ZL and JP conducted the MTT, colony formation, wound healing and Western blot assays and analysis of the data. ZL and YC conducted the migration, Annexin V/PI and tube formation assays and analysis of the data. HY and JL wrote the manuscript. All authors read and approved the final manuscript, and agree to be accountable for all aspects of the research in ensuring that the accuracy or integrity of any part of the work are appropriately investigated and resolved.

\section{Ethics approval and consent to participate}

Not applicable. 


\section{Patient consent for publication}

Not applicable.

\section{Competing interests}

The authors declare no financial or commercial conflict of interest.

\section{References}

1. Rose L: Financial incentives for At-home colorectal cancer screening tests. JAMA Netw Open 2: e191168, 2019.

2. Bray F, Ferlay J, Soerjomataram I, Siegel RL, Torre LA and Jemal A: Global cancer statistics 2018: GLOBOCAN estimates of incidence and mortality worldwide for 36 cancers in 185 countries. CA Cancer J Clin 68: 394-424, 2018.

3. Siegel R, Desantis C and Jemal A: Colorectal cancer statistics, 2014. CA Cancer J Clin 64: 104-117, 2014.

4. Dang YZ, Li P, Li JP, Zhang Y, Zhao LN, Li WW, Wei LC and Shi M: Efficacy and toxicity of IMRT-based simultaneous integrated boost for the definitive management of positive Lymph nodes in patients with cervical cancer. J Cancer 10: 1103-1109, 2019.

5. Lee YH, Kung PT, Wang YH, Kuo WY, Kao SL and Tsai WC: Effect of length of time from diagnosis to treatment on colorectal cancer survival: A population-based study. PLoS One 14: e0210465, 2019.

6. Deng J, Cui J, Jiang N, Zhang R, Zhang L, Hao X and Liang H: STAT3 regulation the expression of VEGF-D in HGC-27 gastric cancer cell. Am J Transl Res 6: 756-767, 2014.

7. Chen C, He W, Huang J, Wang B, Li H, Cai Q, Su F, Bi J, Liu H, Zhang B, et al: LNMAT1 promotes lymphatic metastasis of bladder cancer via CCL2 dependent macrophage recruitment. Nat Commun 9: 3826, 2018.

8. Kim HJ, Jo MJ, Kim BR, Kim JL, Jeong YA, Na YJ, Park SH, Lee SY, Lee DH, Kim BH, et al: Overexpression of Romol is an unfavorable prognostic biomarker and a predictor of lymphatic metastasis in non-small cell lung cancer patients. OncoTargets Ther 11: 4233-4246, 2018.

9. Zheng Y, Song D, Xiao K, Yang C, Ding Y, Deng W and Tong S: LncRNA GAS5 contributes to lymphatic metastasis in colorectal cancer. Oncotarget 7: 83727-83734, 2016.

10. Lin J, Feng J, Jin Y, Yan Z, Lai Z and Peng J: Pien Tze Huang suppresses VEGF-C-mediated lymphangiogenesis in colorectal cancer. Oncol Rep 6: 3568-3576, 2016.

11. Podemska-Jedrzejczak Z, Malinska A, Sujka-Kordowska P, Nowicki M, Puslecki M, Jemielity M and Perek B: Vascular restenosis in coronary artery bypass grafting might be associated with VEGF-C/VEGFR-3 signaling pathway. Heart Vessels 33 1106-1120, 2018

12. Li C, Zhu M, Lou X, Liu C, Chen H, Lin X, Ji W, Li Z and Su C: Transcriptional factor OCT4 promotes esophageal cancer metastasis by inducing epithelial-mesenchymal transition through VEGF-C/VEGFR-3 signaling pathway. Oncotarget 8: 71933-71945, 2017.

13. Liu ZY, Qiu HO, Yuan XJ, Ni YY, Sun JJ, Jing W and Fan YZ: Suppression of lymphangiogenesis in human lymphatic endothelial cells by simultaneously blocking VEGF-C and VEGF-D/VEGFR-3 with norcantharidin. Int $\mathbf{J}$ Oncol 41: $1762-1772,2012$

14. Deng H, Zhou T, Mo X, Liu C and Yin Y: Low-density lipoprotein promotes lymphatic metastasis of esophageal squamous cell carcinoma and is an adverse prognostic factor. Oncol Lett 17: 1053-1061, 2019.

15. Dai $\mathrm{Y}$, Tong R, Guo $\mathrm{H}, \mathrm{Yu} \mathrm{T}$ and Wang $\mathrm{C}$ : Association of CXCR4, CCR7, VEGF-C and VEGF-D expression with lymph node metastasis in patients with cervical cancer. Eur J Obstet Gynecol Reprod Biol 214: 178-183, 2017.

16. Liu X, Wu J, Zhang D, Wang K, Duan X and Zhang X: A network pharmacology approach to uncover the multiple mechanisms of Hedyotis diffusa Willd. on colorectal cancer. Evid Based Complement Alternat Med 2018: 6517034, 2018.

17. Wang C, Zhou X, Wang Y, Wei D, Deng C, Xu X, Xin P and Sun S: the antitumor constituents from Hedyotis diffusa Willd. Molecules 22: E2101, 2017.
18. Chen WJ, Jin YY, Yang H, Wei LH and Lin JM: Hedyotis diffusa Willd reduces migration and invasion through inhibition of TGF- $\beta$-induced EMT in colorectal cancer cells. Eur J Intre Med 23: 57-63, 2018.

19. Li Q, Lai Z, Yan Z, Peng J, Jin Y, Wei L and Lin J: Hedyotis diffusa Willd inhibits proliferation and induces apoptosis of 5-FU resistant colorectal cancer cells by regulating the PI3K/AKT signaling pathway. Mol Med Rep 17: 358-365, 2018.

20. Yan Z, Feng J, Peng J, Lai Z, Zhang L, Jin Y, Yang H, Chen W and Lin J: Chloroform extract of Hedyotis diffusa Willd inhibits viability of human colorectal cancer cells via suppression of AKT and ERK signaling pathways. Oncol Lett 14: 7923-7930, 2017.

21. Lai Z, Yan Z, Chen W, Peng J, Feng J, Li Q, Jin Y and Lin J: Hedyotis diffusa Willd suppresses metastasis in 5-fluorouracil-resistant colorectal cancer cells by regulating the TGF- $\beta$ signaling pathway. Mol Med Rep 16: 7752-7758, 2017.

22. Feng J, Jin Y, Peng J, Wei L, Cai Q, Yan Z, Lai Z and Lin J: Hedyotis diffusa willd extract suppresses colorectal cancer growth through multiple cellular pathways. Oncol Lett 14: 8197-8205, 2017

23. Li Y, Wang X, Wang X, Wan L, Liu Y, Shi Y, Zhang L, Fang Z and Wei Z: PDCD4 suppresses proliferation, migration, and invasion of endometrial cells by inhibiting autophagy and NF-кB/MMP2/MMP9 signal pathway. Biol Reprod 99: 360-372, 2018.

24. Cao L, Liu Y, Wang D, Huang L, Li F, Liu J, Zhang C, Shen Z, Gao Q, Yuan W and Zhang Y: MiR-760 suppresses human colorectal cancer growth by targeting BATF3/AP-1/cyclinD1 signaling. J Exp Clin Cancer Res 37: 83, 2018.

25. Kodera Y, Katanasaka Y, Kitamura Y, Tsuda H, Nishio K, Tamura T and Koizumi F: Sunitinib inhibits lymphatic endothelial cell functions and lymph node metastasis in a breast cancer model through inhibition of vascular endothelial growth factor receptor 3. Breast Cancer Res 13: R66, 2011.

26. Sammarco G, Varricchi G, Ferraro V, Ammendola M, De Fazio M, Altomare DF, Luposella M, Maltese L, Currò G, Marone G, et al: Mast cells, angiogenesis and lymphangiogenesis in human gastric cancer. Int J Mol Sci 9: E2106, 2019.

27. Huang $C$ and Chen Y: Lymphangiogenesis and colorectal cancer. Saudi Med J 38: 237-244, 2017

28. Wang J, Huang Y, Zhang J, Wei Y, Mahoud S, Bakheet AM, Wang L, Zhou $S$ and Tang J: Pathway-related molecules of VEGFC/D-VEGFR3/NRP2 axis in tumor lymphangiogenesis and lymphatic metastasis. Clin Chim Acta 461: 165-171, 2016.

29. Tao P, Wen H, Yang B, Zhang A, Wu X and Li Q: miR-144 inhibits growth and metastasis of cervical cancer cells by targeting VEGFA and VEGFC. Exp Ther Med 15: 562-568, 2018.

30. Lin J, Wei L, Shen A, Cai Q, Xu W, Li H, Zhan Y, Hong Z and Peng J: Hedyotis diffusa Willd extract suppresses Sonic hedgehog signaling leading to the inhibition of colorectal cancer angiogenesis. Int J Oncol 42: 651-656, 2013.

31. Zhang J, Tang H, Zhang YM and Zhang TL: Toxicological safety of Hedyotis diffusa. J Toxicol 28: 249-252, 2014 (In Chinese).

32. Naim A, Pan Q and Baig MS: Matrix metalloproteinases (MMPs) in liver diseases. J Clin Exp Hepatol 7: 367-372, 2017.

33. Jing ZT, Liu W, Wu SX, He Y, Lin YT, Chen WN, Lin XJ and Lin X: Hepatitis B virus surface antigen enhances the sensitivity of hepatocytes to Fas-mediated apoptosis via suppression of AKT phosphorylation. J Immunol 201: 2303-2314, 2018.

34. Xiang L, Xie G, Ou J, Wei X, Pan F and Liang H: The extra domain $\mathrm{A}$ of fibronectin increases VEGF-C expression in colorectal carcinoma involving the PI3K/AKT signaling pathway. PLoS One 7: e35378, 2012.

35. Zhu C, Qi X, Chen Y, Sun B, Dai Y and Gu Y: PI3K/Akt and MAPK/ERK1/2 signaling pathways are involved in IGF-1-induced VEGF-C upregulation in breast cancer. J Cancer Res Clin Oncol 137: 1587-1594, 2011.

36. Peng X, Wang Z, Liu Y, Peng X, Liu Y, Zhu S, Zhang Z, Qiu Y, Jin M, Wang R, et al: Oxyfadichalcone $\mathrm{C}$ inhibits melanoma A375 cell proliferation and metastasis via suppressing PI3K/Akt and MAPK/ERK pathways. Life Sci 206: 35-44, 2018.

37. Zhou S and Sakamoto K: Pyruvic acid/ethyl pyruvate inhibits melanogenesis in B16F10 melanoma cells through PI3K/AKT, GSK $3 \beta$, and ROS-ERK signaling pathways. Genes Cells 24: 60-69, 2019. 